\title{
Ecological Residential Community Site Selection Method Study under Environmental Requirements
}

\author{
Chen Qiu" a \& Yaozhi Huang ${ }^{1, b^{*}}$ \\ ${ }^{1}$ Suzhou University of Science and Technology, Suzhou, Jiangsu, China \\ a1013532125@qq.com, bhpxxx007@163.com
}

\begin{abstract}
Keywords: ecological residential community, environmental requirement, site selection method Abstract. The prior problem of ecological residential community's construction and development is site selection. The article starts with relevant concepts of ecological residential community, with site selection problems as breakthrough point; it analyzes site selection's environmental requirements from both natural and artificial aspects, and proposes corresponding site selection method, especially detailed site selection method made for water network area in the south of Jiangsu, to build better ecological residential community.
\end{abstract}

\section{Introduction}

With the continuous improvement of living standard, people pay more and more attention to the quality of residential environment; ecological environment and its sustainable development of human residential community become a hot issue concerned by all mankind. In 1996, what mentioned in Istanbul Declaration on human settlement has pointed out, "as we are moving into the 21st century, we are looking forward to sustainable human settlements, hoping for our common future. We propose to face up to this rare and attractive challenge. Let us work together to build this world, so that everyone has a safe home and owes a better life with dignity, health, safety, happiness and full of hope"[1]. Urban ecological residential community meets the requirements of human habitation. In recent years, China has also become more and more concerned about the construction and development of ecological residential community.

During domestic cities' new residential community construction, so far there are only a few who clearly put forward the construction of "ecological residential community", and the proportion of ecological residential community is very low in our country, and those ecological residential communities are mainly distributed in more developed areas such as Shanghai, Shenzhen, etc. Domestic research of ecological residential community is mainly concentrated on aspects such as basic concept research, plan designing concept, evaluation index system, development and trends, and so on; and this article research on the aspect of ecological residential community site selection under environmental requirements.

\section{Concept and features of ecological residence}

Domestic and foreign scholars have different understanding of the connotation concerning "ecological residential community". Foreign scholars' understanding of ecological residential community is representative as Global Eco-village Network. The ecological residential community mainly includes social aspect, ecological aspect and cultural aspect[2]. They think that ecological residential community is a kind of sustainable way of life, and integrates ecological design, ecological construction, green products, alternative energy sources, etc. Scholars of our country put forward several kinds concepts with different emphasis of ecological residential community: (1)Professor Zhu Xijin regards that ecological residential community is based on the respect for human survival rights, and a kind of recognition that those with good quality is the foundation of economic and social development. It also stresses the direct function of environment to human. In addition, the concept of ecological residential community also attaches importance to ecological function [3]. (2)Some scholars focus on the aspect of ecological technology, Professor Nie Meisheng 
thinks that green ecological residential community is a balanced development of the land, energy, water, gas, sound, light, heat, water, waste management and green building materials, etc [4]. The planning and construction should follow the development of the natural ecological laws and local residential requirements, with the goal of sustainable development, based on the Ecology, center on human and natural harmony, with modern science and technology as a method, to promote healthy, efficient, civilized, comfortable and sustainable human settlements.(3)The recipient of Sophie prize, Liao Xiaoyi, comprehends the ecological residential community from the view of life style. She thinks the construction of ecological residential community includes not only planning, construction, allocation of energy, but also the residents' way of life.

Compared with the ordinary residential community, the ecological residential community has its own characteristics. The ecological characteristics of ecological residential community is mainly reflected by the ecological characteristics of residential monomer and living environment. As the developing direction of the construction of residence, ecological residential community is more humane and more respect for nature. It has better living conditions. The next table (Table 1) has a comparison between ordinary residential community and ecological residential community [5]. Table 1. Comparison between ordinary residential community and ecological residential community.

\begin{tabular}{|c|c|c|}
\hline & Ordinary residential community & Ecological residential community \\
\hline $\begin{array}{l}\text { Monomer } \\
\text { building }\end{array}$ & $\begin{array}{l}\text { Single architectural design; } \\
\text { Homogeneous residential plane; } \\
\text { Large energy consumption in } \\
\text { residential use; } \\
\text { Lack of living facilities and } \\
\text { inconvenient design. }\end{array}$ & $\begin{array}{l}\text { To maintain regional characteristics and } \\
\text { historical context in architectural design ; } \\
\text { Diversified housing; } \\
\text { The use of ecological technology, and } \\
\text { conservation of resources and energy; } \\
\text { Complete residential facilities and } \\
\text { user-friendly design. }\end{array}$ \\
\hline $\begin{array}{l}\text { Overall } \\
\text { layout }\end{array}$ & $\begin{array}{l}\text { Destroy of the surface appearance for } \\
\text { traffic organization; } \\
\text { Mutual isolation among residents; } \\
\text { Ignorance of microclimate in Planning } \\
\text { and construction of physical layout; } \\
\text { Isolation from natural surrounding; } \\
\text { Artificial nature. }\end{array}$ & $\begin{array}{l}\text { Appropriate traffic to maintain the surface } \\
\text { appearance; } \\
\text { Maintain neighborhood relationship; } \\
\text { Planning and layout of the building with the } \\
\text { consideration of microclimate coordination; } \\
\text { Organic combination with the surrounding } \\
\text { environment; } \\
\text { Keep organic ecosphere. }\end{array}$ \\
\hline
\end{tabular}

\section{Environmental requirement of ecological resistance site selection}

Ecological residential community site selection is influenced by many factors, and the environment is one of the main factors. Environmental factors are divided into natural environment factors and artificial environment factors. Suitable environment for the construction of ecological residential community has a multiplier effect. So it is necessary to clarify the principles and requirements needed to be met in the process of selecting the ecological residential community site. On this basis, we can adjust measures to local conditions and determine a good site, in order to create a suitable living environment. The environmental requirements of ecological residential community site selection is divided into two categories: natural environmental requirements, including topography, geological conditions; the second is artificial environmental requirements, including traffic conditions, the surrounding built environment and other aspects.

Natural environmental requirements. The first thing to consider in site selection is residential community's requirement of natural resource and natural environment. A healthy and ecological environment is a basic demand of ecological residential community, there is no ecological residential community without a good natural environmental foundation, which makes a high request of site selection. Thus, requirements of natural environment in site selection mean a lot. 
The ideal condition of site selection is to pick a place with superior landscape and terrific landform with mountains and rivers, according to Fengshui theory, the best site should meet a criterion, "hills in the back and water in front". An ecological residential community has a hill in the back to block the cold winter wind and water in front to embrace the cool south wind; this kind of site could obtain great sunshine as well as conserve most water and soil. A site selected by the above principal can help forming a superior microclimate as well as a virtuous ecological recycling.

Nowadays, it is obviously unrealistic for each ecological residential community to have a natural environment of "hills in the back and water in front" [6]. However, it's still necessary to have certain requirements for natural environment: (1)Beautiful natural landscape, rich natural resource, both own and utilize surrounding natural environment and visual view.(2)Good geography conditions, good soil bearing capacity, gentle terrain slopes and superior natural geographic location.(3) Choose area with advantageous landform, microclimate and good vegetation.

Artificial environment requirements. The concept of ecological residential community not only has requirements for natural environment that it should have natural ecological system features to reach a harmony between human and nature, but also has requirements for artificial environment. The basic function of ecological residential community is to fulfill human's basic need of residential community, but it has higher requirements than normal residential community in ecological aspect. Residential community is people-oriented, so during the site selection of ecological residential community, we have to take human factors and artificial environment into consideration. Construction of ecological residential community should take requirements of artificial environment into account, including traffic conditions, surrounding emission sources, urbanization level, technology level, traditional culture, folk customs, etc.

Traffic condition is a main factor that affects ecological residential community site selection. Convenient external traffic condition is advantageous for external contact of ecological residential community and convenient for living; on the contrary, inconvenient external traffic conditions have certain effect on residents' daily life. Some built ecological residential community might have focused too much on natural environment and neglected traffic condition of the location. Convenient traffic is good for residents' green low-carbon commuting and reduces private car commuting which is an important embodiment of ecology in a way. Therefore, ecological residential community site selection has certain requirements for surrounding traffic conditions, that is how many directions surrounding roads lead to and how perfect public transit facilities are.

To stay far away from emission source is an important factor of ecological residential community site selection. If surrounding noise, light, air and water are polluted, it would affect the overall environment of ecological residential community, and a healthy living environment of the residential community cannot be assured. So ecological residential community site selection has certain requirements for its surrounding, and should be far away from emission source.

In ecological residential community site selection, sustainable development needs of local artificial features should also be taken into consideration. Ecological residential community should keep local artificial features, protect, inherit and develop traditional culture essence, highlight local characteristics.

\section{Ecological residential community site selection methods under environmental requirements}

Based on the analysis of environmental requirements, I propose following ecological resistance site selection method. Due to the vast territory and multiple cultures of our country, and the huge natural, artificial and landscape difference, different regions should use different featured site selection method. This article will take the water network area in the south of Jiangsu as an example to propose more detailed site selection method from the perspective of both natural environmental requirements and artificial environmental requirements.

Site selection method based on natural environmental requirements. Survey engineering geological conditions. First of all, all residential community should avoid poor engineering geological condition such as complex geological conditions, poor soil bearing capacity, low terrain with poor drainage, etc; meanwhile it should avoid wind gap, slide, and flood erosive areas. Thus, 
survey of engineering geological conditions is necessary in ecological site selection to see if it meets construction requirements. The geographic condition of water network area in the south of Jiangsu is complex; earth foundation is mainly formed in Yanshan movement in late Mesozoic with frequent tectonic movements. Otherwise, the underground water is mainly loose rock pore water with good quality, wide distribution and high degree of utilization; But long-term exploration of underground water have led to water level decrease and serious land subsidence. Therefore, as for site selection of water network area in the south of Jiangsu, detailed survey and evaluation of geological conditions and engineering geological conditions such as land subsidence should be taken at the early stage.

Protect natural environment. Based on requirements of natural environment, priority selection of ecological residential community should be a place with great natural environment. However, once ecological resistance site is determined, the processes from the beginning of construction till the completion of residential community may have certain negative effect to natural environment. So people should try to reduce damage of terrain, landform, natural water system and forest, and avoid taking up nature reserve and endangered animals' habitat. Meanwhile, the residential community should be planned and designed according to circumstances, and a symbiosis should be built with natural surroundings to reduce damage to the natural environment by site construction. Take some site environment recovering measures; and try to make up for inevitable influence to the environment caused by exploitation. In addition, if there is any inevitable natural disaster in the site area, related measures should be taken to deal with natural disasters such as earthquake, fire, debris flow, landslide, etc to ensure safety of the living environment. Meanwhile, ecological residential community should adopt new technology and new materials to enhance disaster prevention performance of the residential community. The area in the south of Jiangsu has plenty of rivers, and this natural feature should be emphasized during site selection of ecological residential community, so as to utilize abundant water resource to satisfy the need of resource and landscape.

Create surrounding landscape. Before site selection of ecological residential community, surrounding scenery factors should be fully used and characteristic landscape can be created by utilizing surrounding scenery wisely. Meanwhile, landscape design of the residential community should conform to the surrounding scenery, and integrate into the surrounding visual scenery environment. Due to the warm and rainy climate and unique water network, scenery of "residential community in misty rain" and "residential community near the river" is formed in the south of Jiangsu. This scenery should be taken into consideration at the early stage of site selection.

Site selection method based on artificial environment requirements. Choose the site with perfect traffic system. In order to obtain good traffic conditions, surrounding traffic infrastructure should be considered in ecological residential community site selection. There should be great public transport facilities near the site and at least one public transport line, and should be able to provide parking area up to the standard. In addition, when the site is chosen, internal traffic needs should be taken into consideration in the planning and designing of ecological residential community, both internal and external traffic system of ecological residential community should be improved. Most cites in water networked area in the south of Jiangsu are promoting public transportation priority policy, take Suzhou as an example, land plots with superior public transportation conditions become first choice of residential development. Especially with the opening of metro line, there are many residential community gathering along metro line. Therefore, ecological residential community should be in a site of great traffic conditions, good public transportation in particular.

Be respect for historical architectures. Before site selection, surrounding historical and cultural architectures should be carefully studied, and protection of the space and environment of conservation districts of historic sites should be emphasized. Architecture density and height of ecological residential community should be controlled within the scope of national and city planning regulations. Architecture shape and dimension should be in respect of formed city space, cultural features and scenery. Most architectures in water network area in the south of Jiangsu has the feature of white walls and black roof-tiles, so surrounding historical architecture should be considered during site selection, and respect should be paid to the spatial pattern, architectural form, lifestyle and culture of Jiangsu traditional water town [7]. 
Choose the site away from emission sources. Stay away from emissary sources during site selection, avoid the downwind and downstream direction of emission sources, make sure of the cleanliness of water and air; if there is any industrial estate nearby, then keep certain pollution purification distant with the industrial zone to avoid pollution of air, water, noise, chemicals and light, etc. Meanwhile, take measures such as noise barrier and plant cover in the late stage of residential community design to reduce noise and enhance air quality to the utmost extent.

Land reused is the first choice. Use land for redevelopment in the first place during ecological residential community site selection is an important embodiment of resource saving aimed ecological concept. Form the aspect of land saving, ecological residential community should be encouraged to use developed land (especially waste lands). So far there are a lot of aging residential community, old unsafe buildings, and waste land due to factory relocation in our country. Give priority to developed areas with urban renewal potential, reuse these lands, and make full use of existing basic facilities to enhance its service efficiency.

\section{Summary}

With people pay more and more attention to healthy ecological life, ecological residential community construction is gradually developing in cities. However, so far our country is still in the early stage of ecological residential community construction with many problems to be discussed, researched and solved. Although ecological residential community site selection is a small topic, it is one of the prior problems we face in future ecological residential community construction. We should pay more attention to residential community site selection problem. Site selection should be considered under the guidance of environmental requirements, including the survey of engineering geological conditions, protection of natural environment, creation of surrounding landscape, perfect transportation system, combination with the surrounding built environment and so on. And these criteria lay a solid foundation for ecological residential community construction.

\section{References}

[1] Liangyong Wu. Introduction to the Science of Human Settlements. Beijing:China Building Industry Press. 2001.

[2] Shengnan Liu. Research on the realization technology of eco residential area. Heibei:Hebei University of Technology. 2007.

[3] Xijin Zhu. Human ecological residential area planning of twenty-first Century. Urban Planning Forum, 1994 (5).

[4] Meisheng Nie. Technical assessment manual of ecological residential area in China. Beijing: China Building Industry Press. 2007.

[5] Yan Tang \& Yingxia Yun. Several Related Problems of Ecological Residential Area on Planning. Planner, 2000.

[6] Shixing Jiao \& Chuanming Leng. The Enlightenment of "Fengshui" Pattern to Ecological residential community Location. Journal of Chongqing Jianzhu University, 2003. 25(6).

[7] Yiru Huang, Yong He \& Ge Guo. The Operational Strategies of Eco-residential community Planning and Design Based on the Conditions "Then and There" - A Case Study on the Xingming Residential Project in Chong ming, Shanghai. Urban Planning Forum, 2008(6):65-72. 